\title{
Position Analysis Of 3-DOF 3-RPS Parallel Manipulator
}

\author{
Khalid Ali Abdelaziz Ali and Ying Liu \\ Key Laboratory of High Speed Cutting \&Precision Machining, Tianjin University of Technology and Education, Dagu nanlu road, \\ Tianjin, China
}

\begin{abstract}
A new three Degree Of Freedom (3-DOF) parallel manipulator has been proposed in this study. Because the parallel manipulator has three Degree Of Freedom (DOF), one translation degree of freedom and two rotational degrees of freedom. The model is established by using UG 8.0 and The inverse kinematic analysis and simulation results using ADAMS.
\end{abstract}

Keywords-design and modeling; inverse kinematic analysis; simulation using ADAMS; results

\section{INTRODUCTION}

The design of parallel manipulators can be trace back to 1962, when Gough and Whitehall (1962) devised a six-linear jack system for used as a universal tire- testing machine. Stewart (1965) designs a platform manipulator for use as an aircraft simulator in 1965 . Since then a systematic study of the kinematic structure of parallel manipulators in 1983 was performed by Hunt (1983). Parallel manipulators have been studied extensively by numerous researchers (Clearly and Arai, 1991; Fitcher , 1986; Grffis and Duffy, 1989; Innocenti and Parenti-Castelli, 1990; Mohamed and Duffy, 1985; Nanua et al., 1990; Zhang and Song, 1994) [1]

Parallel platform is gaining popularity and widely used in many applications with the development and application of virtual reality technology which include among others, vehicle driving simulator, parallel kinematic machine, flight simulator, simulation of seismic waves, pointing and polishing machine and earthquake wave simulator etc. Moreover, it continue to expand into new application areas[2].Parallel manipulator is a field of interest for a many researchers due its diversified applications, high accuracy and speed more than serial manipulator.

Researchers are battling to come up with new ideas on how to deal with the working space problem of the manipulator without compromising the other design parameters. Its accuracy and repeatability is an attribute to its high stiffness and low inertia and also it has great ability to withstand heavy load due to the fact that the load is merely assumed to be distributed to the platform which in turn the platform is supported by limbs., the parallel robots consists of fixed base which might be of various shapes depend on designers choice and applications intended to performed, but usually the base shape is not playing an important role during the application. Attached to the base are limbs which is an assembly of more than one joint, the joint assembly also depend on the designers choice. Attached to the limbs of the parallel robot is the moving platform which served as end effectors[1] .

Because parallel manipulator has characteristics as above, it is able to be used as vehicle driving simulator. When it is used as vehicle driving manipulator, there are many advantages such as low cost, professional driver training, high precision, safety, and so on.

\section{MOdELING USING UG8.0}

Design the parts of $3 \mathrm{DOF}$ parallel manipulator and assembly modeled by using UG 8.0.

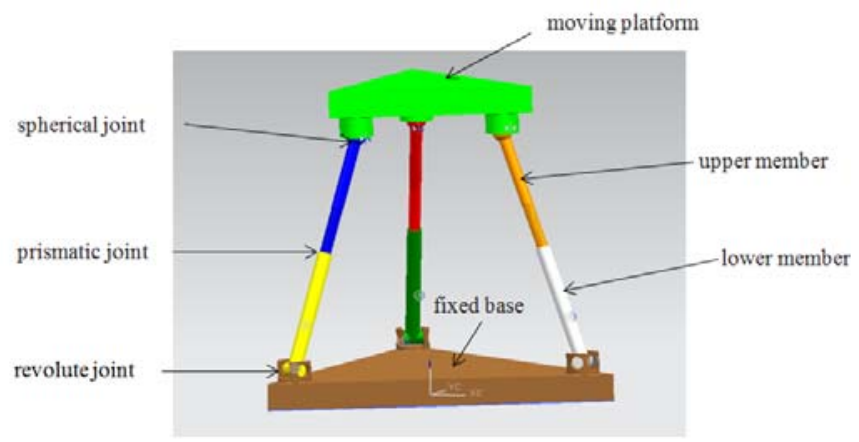

FIGURE I. 3 DOF PARALLEL MANIPULATOR IN UG

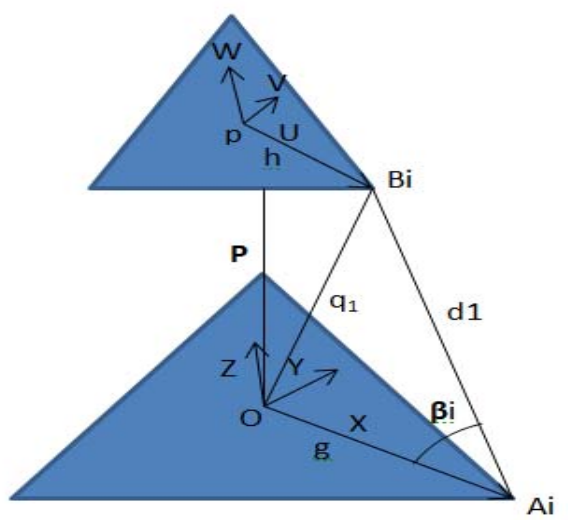

FIGURE II. 3 DOF PARALLEL MANIPULATOR 
TABLE I. THE DESIGN SPECIFICATION

\begin{tabular}{|c|c|}
\hline Base radius $(\mathrm{mm})$ & 600 \\
\hline Manipulator radius $(\mathrm{mm})$ & 352.7865 \\
\hline $\begin{array}{c}\text { Limb length from the center line of the R joint to centre of } \\
\text { the S joint }(\mathrm{mm})\end{array}$ & 800 \\
\hline Distance between the fixed base and spherical joint & 895.6449 \\
\hline Distance between the manipulator centers $(\mathrm{mm})^{\text {Limb angle }}{ }^{\circ}(\beta \mathrm{i})$ & 870.7708 \\
\hline Distance from fixed frame to revolute joint $(\mathrm{mm})(\mathrm{g})^{\circ}$ & 500 \\
\hline Distance from moving frame to spherical joint $(\mathrm{mm})(\mathrm{h})$ & 252.7865 \\
\hline $\mathrm{p}_{\mathrm{z}}$ distance $(\mathrm{mm})$ & 860.845 \\
\hline
\end{tabular}

III. INVERSE KINEMATIC ANALYSIS

For the inverse kinematics problem, the position vector $p$ and the rotation matrix $\mathrm{aRb}$ of frame $\mathrm{B}$ with respect to $\mathrm{A}$ are given and the limb length di , $\mathrm{i}=1,2,3$ are to be found. Consider the Platform in figure II [3].

The length ith of the leg is given by

$$
\mathrm{di}=\mathrm{p}+{ }^{\mathrm{A}} \mathrm{R}_{\mathrm{B}}{ }^{\mathrm{B}} \mathrm{bi}-\mathrm{ai}
$$

From Figure2, the location of the $i^{\text {th }}$ attachment point $\left(b_{i}\right)$ on the moving platform can be found, $\boldsymbol{b}_{\boldsymbol{i}}$ and $\boldsymbol{a}_{\boldsymbol{i}}$ are the radius of the moving platform and fixed base, respectively.

$$
b_{i}=\left[b_{i u}, b_{i v}, b_{i w}\right]^{T}, a_{i}=\left[a_{i x}, a_{i y}, a_{i z}\right]^{T}
$$

${ }^{\mathrm{B}} \mathrm{b}_{1}=\left[\begin{array}{lll}\mathrm{h} & 0 & 0\end{array}\right]^{\mathrm{T}},{ }^{\mathrm{B}} \mathrm{b}_{2}=\left[\begin{array}{lll}-0.5 \mathrm{~h} & 0.866 \mathrm{~h} & 0\end{array}\right]^{\mathrm{T}},{ }^{\mathrm{B}} \mathrm{b}_{3}=\left[\begin{array}{lll}-0.5 \mathrm{~h} & -0.866 \mathrm{~h} 0\end{array}\right]^{\mathrm{T}}$

$\mathrm{a}_{1}=\left[\begin{array}{lll}\mathrm{h} & 0 & 0\end{array}\right]^{\mathrm{T}}, \mathrm{a}_{2}=\left[\begin{array}{lll}-0.5 \mathrm{~g} & 0.866 \mathrm{~g} & 0\end{array}\right]^{\mathrm{T}}, \mathrm{a}_{3}=\left[\begin{array}{lll}-0.5 \mathrm{~g} & -0.866 \mathrm{~g} & 0\end{array}\right]^{\mathrm{T}}$

$$
\mathrm{p}=\left[\begin{array}{lll}
\mathrm{p}_{\mathrm{x}} & \mathrm{p}_{\mathrm{y}} & \mathrm{p}_{z}
\end{array}\right]^{\mathrm{T}}
$$

$$
{ }^{\mathrm{A}} \mathrm{R}_{\mathrm{B}}=R_{Z}(\gamma) R_{Y}(\beta) R_{X}(\alpha)=\left[\begin{array}{lll}
U_{x} & V_{x} & W_{x} \\
U_{y} & V_{y} & W_{y} \\
U_{z} & V_{z} & W_{z}
\end{array}\right]
$$

$$
\begin{aligned}
& \text { [cospcosy cosrsinusin } \beta-\cos \alpha \sin \gamma \text { sinosiny }+\cos \alpha \cos \gamma \sin \beta]
\end{aligned}
$$

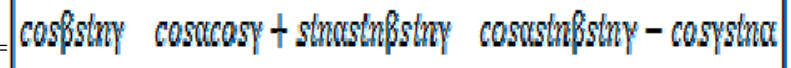

$$
\begin{aligned}
& \sin \beta \quad \cos \beta \sin \alpha \quad \cos \alpha \cos \theta
\end{aligned}
$$

The length of the $i^{\text {th }}$ limb is obtained by taking the. dot product of the vector $d_{i}$ by its self.

$$
d^{2}{ }_{i}=\left[P+{ }^{a} R_{b} . b_{i}-a_{i}\right]^{T}\left[P+{ }^{a} R_{b} . b_{i}-a_{i}\right] \quad \text { for } i=1,2,3
$$

$d^{2}{ }_{i}=\left(p_{x}-a_{x i}+b_{x i} u_{x}+b_{y i} v_{x}\right)^{2}+\left(p_{y-} a_{y i}+b_{x i} u_{y}+b_{y i} v_{y}\right)^{2}+\left(p_{z}+b_{x i} u_{z}+b_{y i} v_{z}\right)^{2}$

Inserting equations (2), (3), (4), (5) into (7) and writing the equation for each limb, $i=1,2,3$ yield

$$
\mathrm{d}_{\mathrm{l}}^{2}=\mathrm{p}_{\mathrm{x}}{ }^{2}+\mathrm{p}_{\mathrm{y}}{ }^{2}+\mathrm{p}_{\mathrm{z}}{ }^{2}+\mathrm{k}_{1}+\mathrm{g}^{2}+\mathrm{h}^{2}
$$

Where

$$
\begin{gathered}
\mathrm{k}_{1}=2 \mathrm{~h}\left(\mathrm{p}_{\mathrm{x}} \cos \beta \cos \gamma+\mathrm{p}_{\mathrm{y}} \cos \beta \sin \gamma-\mathrm{p}_{\mathrm{z}} \sin \beta\right)- \\
2 \mathrm{~g}\left(\mathrm{p}_{\mathrm{x}}+\mathrm{h} \cos \beta \cos \gamma\right) \\
\mathrm{d}_{2}{ }^{2}=p^{2}{ }_{x+} p^{2}{ }_{y+} p_{z}^{2}+k_{2}+\mathrm{g}^{2}+\mathrm{h}^{2}
\end{gathered}
$$

Where

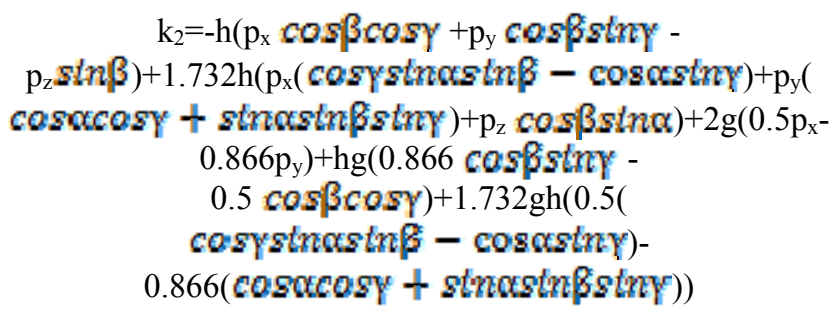

$$
\mathrm{d}_{3}^{2}=p_{x+}^{2} p_{y+}^{2} p_{z}^{2}+k_{3}+\mathrm{g}^{2}+\mathrm{h}^{2}
$$

Where

$$
\begin{gathered}
k_{3}=-\mathrm{h}\left(\mathrm{p}_{\mathrm{x}} \cos \beta \cos \gamma+\mathrm{p}_{\mathrm{y}} \cos \beta \sin \gamma-\mathrm{p}_{\mathrm{z}} \sin \beta\right)- \\
1.732 \mathrm{~h}\left(\mathrm{p}_{\mathrm{x}}(\cos \mathrm{\gamma} \sin \alpha \sin \beta-\cos \alpha \sin \gamma)+\mathrm{p}_{\mathrm{y}}(\right. \\
\left.\cos \alpha \cos \mathrm{\gamma}+\sin \alpha \sin \beta \sin \gamma)+\mathrm{p}_{\mathrm{z}} \cos \beta \sin \alpha\right)+2 \mathrm{~g}\left(0.5 \mathrm{p}_{\mathrm{x}}+0\right. \\
\left..866 \mathrm{p}_{\mathrm{y}}\right)-\mathrm{hg}(0.5 \cos \beta \cos \gamma+0.866 \cos \beta \sin \gamma)- \\
1.732 \mathrm{gh}(0.5(\cos \gamma \sin \alpha \sin \beta-\cos \alpha \sin \gamma)+0.866( \\
\cos \alpha \cos \gamma+\sin \alpha \sin \beta \sin \gamma))
\end{gathered}
$$

\section{LENGTH OF LIMB}

Using matlab for calculate to solve the equations $(8,9,10)$ to get (di). We will add $50-100 \mathrm{~mm}$ for pz and insert $\left(\alpha^{\circ}\right)$ show table II. 
TABLE II. INVERSE KINEMATICS RESULTS IN MATLAB

\begin{tabular}{|c|c|c|c|c|c|c|c|}
\hline $\mathbf{S} / \mathbf{N}$ & $\boldsymbol{\alpha}^{\mathbf{0}}$ & $\boldsymbol{\beta}^{\mathbf{0}}$ & $\boldsymbol{\gamma}^{\mathbf{0}}$ & $\begin{array}{c}\mathbf{P}_{\mathbf{x}} \\
(\mathbf{m m})\end{array}$ & $\begin{array}{c}\mathbf{P}_{\mathbf{y}} \\
(\mathbf{m m})\end{array}$ & $\begin{array}{c}\mathbf{p}_{\mathbf{z}} \\
(\mathbf{m m})\end{array}$ & $\begin{array}{c}\mathbf{C a l} \\
\mathbf{d}_{\mathbf{i}} \mathbf{( \mathbf { m m } )}\end{array}$ \\
\hline 1 & 0 & 0 & 0 & 0 & 0 & 910.845 & 943.7972 \\
\hline 2 & 0 & 0 & 0 & 0 & 0 & 960.845 & 992.1379 \\
\hline 3 & 2 & 0 & 0 & 0 & 0 & 910.845 & 943.7972 \\
\hline 4 & 8 & 0 & 0 & 0 & 0 & 960.845 & 992.1379 \\
\hline
\end{tabular}

V. INVERSE KinEMATIC SimUlation

The manipulator is imported to ADAMS and constrains was applied to the model accordingly with the prismatic joint as the actuated joint as in the chart below. Also force/friction was applied to prismatic joint of each limb with gravitational force of $15680 \mathrm{~N}$ applied to the moving platform centre also the maximum stroke length is $100 \mathrm{~mm}$. For the model in question kinematic simulation. Two different functions were used i.e. SINE FUNCTION and STEP FUNCTION. Both the results are tabulated in Table III.

TABLE III. INVERSE KINEMATICS RESULTS IN ADAMS AND CALCULATION IN MATLAB

\begin{tabular}{|c|c|c|c|c|c|}
\hline $\mathbf{S} / \mathbf{N}$ & Functions & $\begin{array}{l}\text { Length } \\
\text { Increment } \\
(\mathrm{mm})\end{array}$ & $\begin{array}{c}\text { Cal } \\
\text { d }(\mathbf{m m})\end{array}$ & $\begin{array}{c}\text { Sim } \\
\text { d }(\mathbf{m m})\end{array}$ & $\begin{array}{l}\text { Error } \\
(\mathbf{m m})\end{array}$ \\
\hline 1 & $2813.071 d^{*}(1-\sin ($ time $))$ for both the limbs & 100 & 992.1379 & 993.3182 & 1.18 \\
\hline 2 & $\begin{array}{l}2813.071 \mathrm{~d}^{*}(1-\sin (\text { time })), 2813.071 \mathrm{~d}^{*}(1-\sin (\text { time })) \text { and } \\
2813.071 \mathrm{~d}^{*}(1+\sin (\text { time }))\end{array}$ & 100 & 992.1379 & 993.5403 & 1.402 \\
\hline 3 & $\begin{array}{l}1782.817 *(\text { step }(\text { time }, 0,0,1,0.1) \text {-step }(\text { time }, 0,0,2,0.1)) \\
\text { for both the limbs }\end{array}$ & 100 & 992.1379 & 993.3587 & 1.221 \\
\hline 4 & $\begin{array}{l}1782.817 *(\text { step }(\text { time }, 0,0,1,0.1)-\text { step }(\text { time }, 0,0,2,0.1)), \\
1782.817 *(\text { step }(\text { time }, 0,0,3,0.1)-\text { step }(\text { time }, 0,0,6,0.1)) \text {, and } \\
1782.817 *(\text { step }(\text { time }, 0,0,3,0.1)-\text { step }(\text { time }, 0,0,6,0.1))\end{array}$ & 100 & 992.1379 & 991.3614 & 0.777 \\
\hline
\end{tabular}

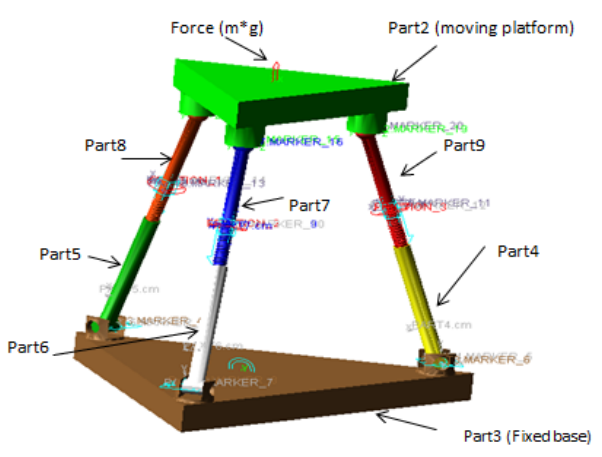

FIGURE III. MODEL BEFORE THE SIMULATION

- $\quad$ Sine Function of $2813.071 \mathrm{~d}^{*}(1-\sin ($ time$))$ were used at each actuated joint of the limb to find the position of the moving prismatic joint parts.

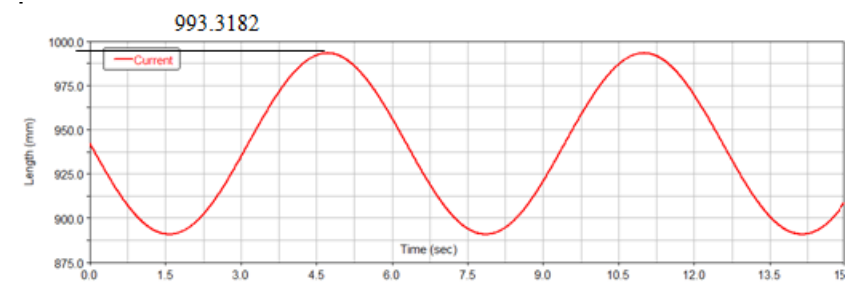

FIGURE IV. PLOT OF TOTAL LIMBS LENGTH AFTER SIMULATION $(100 \mathrm{MM})$
- Sine Function of $2813.071 \mathrm{~d}^{*}(1-\sin ($ time $))$, $2813.071 \mathrm{~d}^{*}(1-\sin ($ time $))$ and $2813.071 \mathrm{~d} *(1+\sin ($ time $))$ were used at first, second and third limb to find the position of the moving prismatic joint parts, force at each prismatic joint.

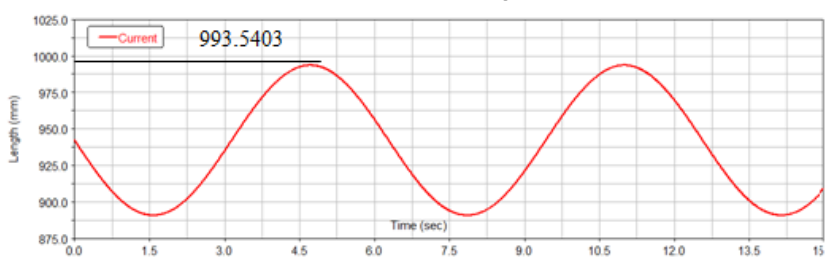

FIGURE V. PLOT OF TOTAL LIMBS LENGTH AFTER SIMULATION (100MM)

- $\quad$ Step Function of $1782.817 *(\operatorname{step}($ time, $0,0,1,0.1)$ step(time, $0,0,2,0.1)$ ), were used at each actuated joint of the limb to find the position of the moving prismatic joint parts.

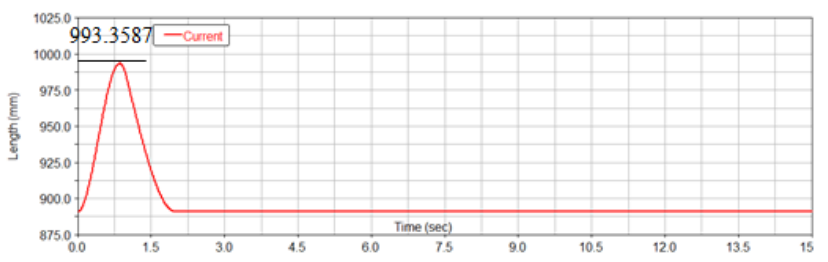

FIGURE VI. PLOT OF TOTAL LIMBS LENGTH AFTER SIMULATION(100MM)

- $\quad$ Step Function of $1782.817 *(\operatorname{step}($ time, $0,0,1,0.1)$ step(time, $0,0,2,0.1)), \quad 1782.817 *($ step(time, $0,0,3,0.1)-$ 
step(time, $0,0,6,0.1)) \quad$ and $\quad 1782.817 *(\operatorname{step}($ time $, 0,0,3,0.1)-$ step(time, $0,0,6,0.1)$ ) were used at first, second and third limb to find the position of the moving prismatic joint parts.

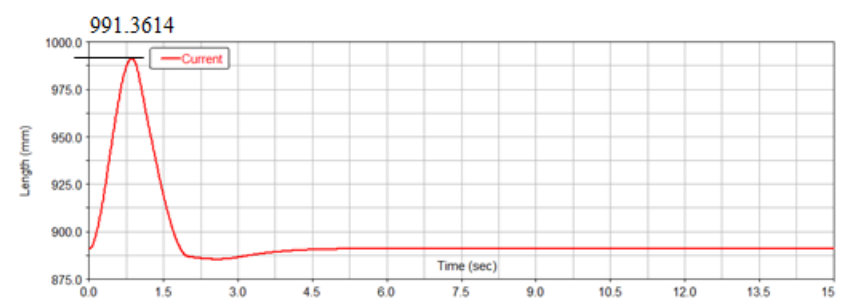

FIGURE VII. PLOT OF TOTAL LIMBS LENGTH AFTER SIMULATION(100MM)

\section{ACKNOWLEDGMENT}

The authors would like to thank the anonymous reviewers for their useful suggestions during the revision of the paper. The authors also would like to thank Scientific Research Development Fund of Tianjin University of Technology and Education (KJY14-02) for his valuable suggestions and kind help.

\section{REFERENCES}

[1] L. W Tsai, Robot Analysis: The Mechanics Of Serial And Parallel Manipulators, Wiley, New York, 1999.

[2] Ginger Shifa, Review and Development of the flight simulator, electrooptical and Control, 1998 (3): 8-12 .

[3] Lung- Wen Tsai , Robot Analysis: The Mechanics Of Serial And Parallel Manipulators, college park Maryland.

[4] Zafer Bingul and Oguzhan Karahan (2012). Dynamic Modeling and Simulation of Stewart Platform, Serial and Parallel Robot Manipulators - Kinematics, Dynamics, Control and Optimization, Dr. Serdar Kucuk (Ed.), ISBN: 978-953-51-0437-7,

[5] J.-P. MERLET ,Parallel Robots , Springer,P.O. Box 17, 3300 AA Dordrecht, The Netherlands.

[6] Youhong Gong "Design Analysis of a Stewart Platform for Vehicle Emulator Systems" Massachusetts Institute of Technology, January 1992. 